PAPER

\title{
Acquiring electric energy from the transport conveyor roller movement for distributed sensors network
}

\author{
Krzysztof Mazurek ${ }^{1}$, Marek Szyguła ${ }^{1}$, Karel Perutka ${ }^{2}$, \\ Krzysztof Turczyński ${ }^{1}$, Krzysztof Stankiewicz ${ }^{1}$
}

\begin{abstract}
The paper presents the concept of installation of an electricity generator and en energy store inside a roller of belt or roller conveyor. Accordingly, the use of a generator-pulley does not require any structural changes to be made to an existing conveyor. In addition, the user will be able to power distributed sensors network for monitoring the operation of the belt conveyor anywhere on its route.

K e y w or d s: belt conveyor, roller conveyor, roller, electricity generator, sensors network
\end{abstract}

\section{Introduction}

Belt conveyors are intended mainly for transportation of run-of-mine in mines, gravel pits, quarries and other plants using belt transportation. Belt conveyors enable fast and efficient transportation of bulk materials of different physical-mechanical properties with low degradation during the movement which often takes place at high speed and over long distances [34]. endless belt, which is set in motion by a driving drum rotated by the engine and slides on the rollers is the component that pulls and transports the run-of-mine. A roller, shown schematically in Fig. 1, consists of the following components: the shell (1), the axle (2), the hub (3) - being the bearing housing (4) and labyrinth seal (5) and the snap rings (6). Depending on the manufacturer and the conditions of use, the rollers may be equipped with additional sealing (7) and closing rings (8).

Due to the important role of the conveyor belt, it is important to monitor its operation, which in general relates to diagnostic symptoms, technological parameters and operating parameters as well as safety parameters [18]. Research work are carried out in many scientific centres to develop monitoring devices to improve the reliability and safety of the belt conveyor. Detailed results of the analysis of conveyor operation parameters, as well as descriptions of research devices used, for example, to monitor the condition of the belt or rollers are presented $[3,9,10,31,32]$. However, supplying power to the testing equipment, located along the entire route of the main conveyor, requires additional electrical installation $[22,23]$. This is particularly difficult and expensive for a mining company, where the length of the underground conveyor belt route can reach up to $20 \mathrm{~km}[2,17]$. In addition, electrical equipment and installations operating in underground workings, classified as potentially explosive, must comply with the ATEX directive [7], which significantly increases the cost of investment in an additional system to power the monitoring equipment. An example of a practical solution that meets the requirements of the ATEX directive on explosion safety is presented in [14-16, 21,32 40-42].

Several technical solutions have been created for electricity generators, which use belt conveyor movement to convert mechanical energy into electricity, however, in each of the known solutions the possibility of using this energy is only possible during the conveyor operation. In

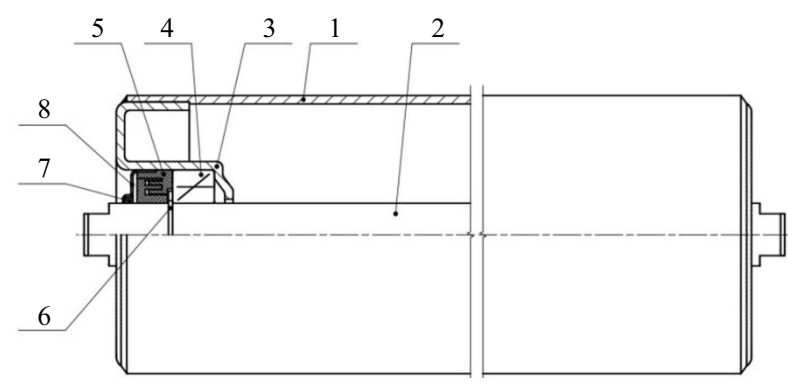

Fig. 1. The roller design: (1) - the shell, (2) - the axis, (3) - the hub, (4) - the bearing housing, (5) - labyrinth seal (5), rings (6) - snap (7) - sealing, (8) - closing, [33]

\footnotetext{
${ }^{1}$ KOMAG Institute of Mining Technology, Pszczynska 37, 44-101 Gliwice, Poland; kmazurek@komag.eu, ${ }^{2}$ Tomas Bata University in Zlin, Faculty of Applied Informatics, Czech Republic
} 
known design solutions, the use of the generator requires a change in the form of the conveyor belt, which in the case of an existing conveyor requires a new approval. In addition, in the case of the main belt conveyor, located in underground workings, the assembly [37] of additional generator holders on the conveyor's trestles can be complicated and time-consuming, and thus expensive, due to the stopped production process in the mine.

Therefore, KOMAG developed a concept for generating electricity from belt conveyor movement [34]. Unlike known technical solutions, the proposed device does not require the use of special holders, stringers or other additional components necessary to install the generator on the belt conveyor.

Mining industry is one of the important branches of Polish economy, where is a high demand for automation of machines and technological processes and which pose a threat to human health and life. To eliminate hazards resulting from human errors the sensors networks and artificial intelligence are used. In the mining industry it is used, among others, in diagnostics of wear of subsystems and components [25] as well as in control of machines and mechanization systems [5, 1343$]$. Implementations enabling intelligent adaptation of machines to change operational conditions are known. Currently, the new mining machines are robotized to high extend and they use innovative methods of programming from cuts memory to programming by gestures. Future mining of thin seams of high methane concentration, threatened by rock bursts and thermal hazards, forces the designers to develop the systems of greater autonomy, so that the role of a man will be limited mainly to supervision.

Implementations of routing protocols based on artificial intelligence technologies and methods are also more and more often met in mine communication systems. Effective routing is especially important in the case of networks built in mesh topology with implemented ad hoc mechanism. Wireless network for monitoring the pressure in hydraulic legs of powered roof support $[12,24]$ or in the system for monitoring the temperature of belt conveyors runners, which is under development, [30] can be an example. ad hoc network is a group of mobile wireless devices, which dynamically creates a temporary network infrastructure without central administration spot. ad hoc network often consists of multihopping structures, where on the section between nodes there can be very low throughput and communication can be realized only in one direction. Nodes in such network are not only the information receivers, but they can also play a role of devices transferring the data to other nodes. Initially, investigations on ad hoc networks were carried out as regards the use of such solutions in army. However, increasing need for communication of devices, which are not in a direct range of transmitters of backbone network, resulted in establishment of Mobile ad hoc Networking (MANET) group and Network Mobility (NEMO) group at the Internet Engineering Task Force (IETF) organization. Testing and standardization of IP routing protocols as regards their use in topologies of both static and dynamic character, built of different types of hardware using wireless communication, are the tasks of both groups. Structurally complex networks of dynamically changing configuration have a series of problems to be solved, most important of which are as follows [4, 6, 8, 11, 19, 20,27-29]:

- mobility - dynamically changing positions of nodes. Unknown number of nodes in each network,

- multihopping - route from the source to targeted place leads through several nodes. Several hops can change in a short time,

- self-organization - ad hoc network must determine independently its configuration parameters such as routing, position and supply parameters,

- energy saving - many devices creating the ad hoc network have supply source of limited energy. Use of energy-optimized protocols enables to extend the time of operation of these devices,

- scalability - a character of ad hoc network enables dynamic building of networks, which can have many nodes,

- safety - ad hoc networks, due to their character, are one of network environments most vulnerable to network attacks.

\section{Electricity generator concept}

The main design assumption was to develop a device for recovering the electricity from the conveyor belt movement without changing the conveyor design. According to the assumption, it was proposed to use the interior of a standard roller of a jacket tube diameter $\varnothing 133 \mathrm{~mm}$ and a working length of $465 \mathrm{~mm}$. It is the roller most used in mine conveyors to support the upper belt. Diagram of the pulley with built-in generator is shown in Fig. 2 .

This roller does not differ from the standard design $[7,10]$, which consists of: a jacket (1), hubs (3) bearing housings (4), labyrinth seal (5), snap rings (6) and additional covers (7) and rubber rings (8). However, the generator (9) could be mounted by dividing the axle into two half shafts (2), which consequently forced the use of double-row spherical roller bearings. The rotation of the generator axle (9), on which the stator is mounted, relative to the shaft (2) of the rotor is blocked by counter nuts (10), while the generator housing (9), in which magnets are placed on the periphery, rotates together with the split spaced rings (11) and the shell (1) of roller. Split spacer rings (11) are made of plastic, which allows the generator housing (9) to fit tightly with the inner wall of the shell (1). The generated electric energy is discharged outside the roller by a wire (12), routed through the channels in the half shaft (2) and through the cable gland (13).

Already existing and proven solutions are suggested to be used in this design, so bicycle hub with electricity generator is used. For example, we can use the front bicycle wheel hub with a built-in dynamo from SHIMANO 


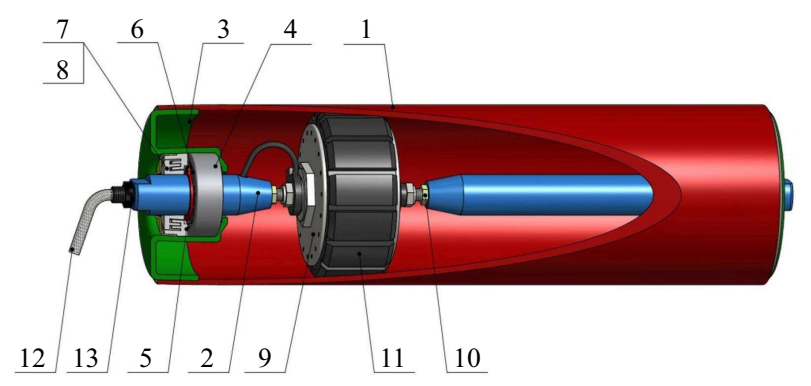

Fig. 2. Layout of the roller with a built-in generator: (1) - shell, (2) - drive shaft, (3) - the hub, (4) - bearings, and (5) - labyrinth seal, (6) - snap rings, (7) - sealing rings (8) - closing rings, (9) - generator, (10) - jam nuts, (11) - split spacer rings, (12) - cable, (13) - cable gland, [33]

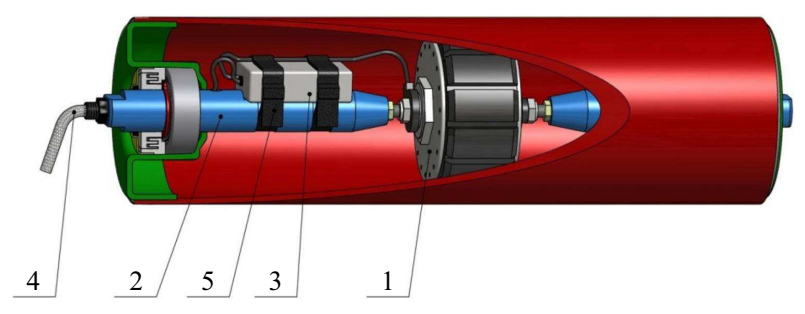

Fig. 3. A diagram of the roller equipped with devices for generating and storing electricity: (1) - dynamo, (2) - drive shaft, (3) - electricity storage device, (4) - cable, (5) - clamps, [33]

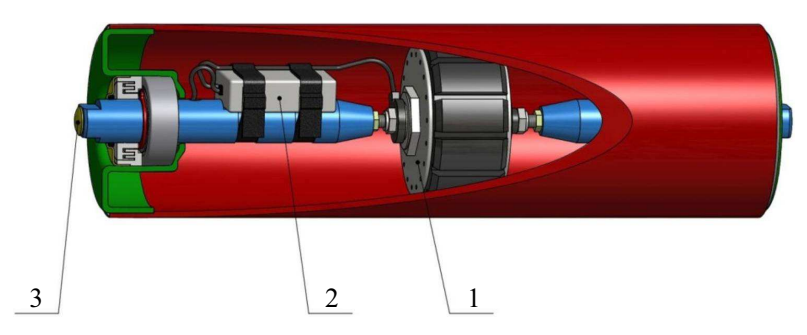

Fig. 4. Diagram of the roller equipped with emergency lighting [33]

model DH-3N31 - $6 \mathrm{~V}$ voltage and $3 \mathrm{~W}$ power [36]. The use of such generators in one roller, connected in parallel, will generate more power. Due to the compact design of the hub with dynamo and spacer ring, this solution can be used in any roller with an inner diameter of the shell tube greater than $\varnothing 110 \mathrm{~mm}$, and the length of the jacket not less than $240 \mathrm{~mm}$.

Direct power supply of the monitoring device poses the risk of temporary downtime in the electricity supply, and thus loss of measurements continuity - this is related to the possible stop of the belt conveyor, whose movement drives the dynamo. Therefore, it is safer to store the generated electricity in batteries supplying the measuring device. In another solution, it is also possible to install the battery pack inside the roller (due to the heat generated during belt friction, the possibility of using a high-temperature cell should be considered). Also, in this case, a ready-made commercial solution equipped with a set of batteries together with their charging system (this system has protection against batteries overcharging) was used. Additionally, a current stabilization system in a dynamo should be used.

A diagram of the roller equipped with devices for generating and storing electricity is shown in Fig. 3.
Figure 3 shows a roller in which the electric energy generated by the dynamo (1) charges the electric energy storage device (3), which, with use of clamps (5), is mounted on the half shaft (2) with a cable (4) and supplies eg monitoring devices.

The roller, which is the subject of this work, can be used not only to power the monitoring equipment, but also may contribute to the improvement of safety along the main conveyor route. Especially, when it is necessary to turn off the power supply of both the conveyor belt and lighting of the working in which the conveyor is located. Another solution is dedicated to the emergency escape lighting system along the conveyor belt route. A roller generating and storing electric energy is additionally equipped with an LED mounted on the front wall of the hal shaft runner. Figure 4 shows a diagram of a roller equipped with emergency lighting - powered by an internal battery.

Similarly, to the roller shown in in Fig. 3, in the solution presented in Fig. 4 the electricity generated by the dynamo (1) charges the electricity storing device (2), which supplies LED (3). It is possible to connect the power supply system with the programmer activating the 
appropriate lighting sequence, then the program is activated by pressing the diode housing - which also acts as a switch.

In addition, emergency lighting systems can be connected to the roller generating electricity, indicating the crew's escape route. We can program the lighting control system so that:

- during operation of the belt conveyor, the lighting is steady, while during stoppage it is pulsating,

- during operation of the belt conveyor the lighting is turned off, while during stopping it lights with a steady or pulsating light,

- both during operation and stoppage, the belt conveyor lighting is off.

\section{Wireless communication system of sensors network powered by rollers generators}

Since 2012, ITG KOMAG has been developing the concept of a protocol of self-organizing communication structure, named SSKIR [30], which is based on one of artificial intelligence technologies, "swarm intelligence", which is a direct implementation of phenomena and behaviour observed in nature among organisms living in large groups. Their behaviour, to some extent, can be transferred to the operation of routing protocols. The system structures developed by humans (irrespectively to real implementation), using the swarm algorithm, have high possibilities for adaptation and high operational reliability. In 1987, during the SIGGRAPH conference, a programmer, Craig Reynolds, in the paper entitled Flocks, Herds, and Schools: A Distributed Behavioural Model, suggested three basic rules of self-organization based on observed groups of animals, as follows [26]:

- collision avoidance is control eliminating a local concentration of individuals. Collision avoidance eliminates accumulation of hardware and decision structures,

- flock centring are actions towards the average behaviour of local groups of individuals,

- velocity matching are actions towards the average objective of local groups of individuals. Velocity matching enables the individual to adapt its actions to other individuals from its local group.

Based on the above rules, the creation of a communication system made of a sensor network (Fig. 5) in which routing is based on a swarm algorithm was suggested [30]. Each data frame transferred by the Measure Transmission Unit (MTU) is marked by a quality coefficient $\Omega_{\Pi}$ specifying the transmission priority referring to the effectiveness of data transmission to the main transceiver stations. This coefficient can take a value that conforms to one of connections or path metrics $[1,4,6]$.

As mentioned above, the $\Omega_{\Pi}$ coefficient can take a value that conforms to one of connections or path metrics; therefore, transmission speed and the number of hops of transmitted frames containing the following measurement data is based on data propagation times:

- Expected Transmission Count (ETX) is a metric that is widely used in mesh networks. ETX is the metric specifying the number of expected transmissions, which is indispensable when sending data to the next node without errors. The number varies from 1 to infinity. An ETX metric equal to 1 indicates a perfect data transmission path, and an ETX approaching infinity represents the connection that is not functioning.

- Expected Transmission Time (ETT) is an extension of ETX metrics, since it takes into consideration the difference in the speed of data transmission. The ETT of connection 1 is defined as an expected duration of the successful transmission of a data package in connection 1. The importance of $\mathrm{p}$ path is defined as a sum of the ETT of all possible connections along the given path. The relationship between ETT and ETX can be expressed as follows:

$$
E T T_{l}=E T X_{l} \frac{s}{b_{l}}
$$

where, $b_{l}$ is the speed of transmission of information in connection $l$ and $s$ is the size of transmitted package.

- Hop count is the most often used routing metric in the existing routing protocols, such as DSR (Dynamic Source Routing), AODV (ad hoc On-Demand Distance Vector), or DSDV (Destination-Sequenced Distance Vector). Hop count is the routing measure used to measure a distance between transmitting and receiving stations counting the hops. The next hop can be a receiving station or device intermediating in the exchange of information. The protocol using the Hop count metric determines the route with the lowest number of hops between transmitting and receiving stations.

- Weighted Cumulative ETT (WCETT) is a metric that includes both the quality of a connection (losses, throughput) and the number of hops. Thus, we can reach a compromise between delay and throughput.

$$
W C \operatorname{ETT}(p)=1-\beta \sum_{l \in p} E T T_{l}+\beta \max _{1 \leq j \leq k} X_{j}
$$

where $\beta$ is a set parameter from the range $0 \leq \beta \leq 1$. Higher values of $\beta$ give priority to paths using many channels and its lower values give priority to shorter paths,

- MIC is metric that improves the operation of WCETT by solving its isotonicity and inability of detecting the collisions. MIC metrics of $p$ path can be defined as follows

$$
W C E T T(p)=1-\beta \sum_{l \in p} E T T_{l}+\beta \max _{1 \leq j \leq k} X_{j}
$$

where, $N$ is the number of all nodes in the network, $\min (\mathrm{ETT})$ is the lowest ETT in the network and it 


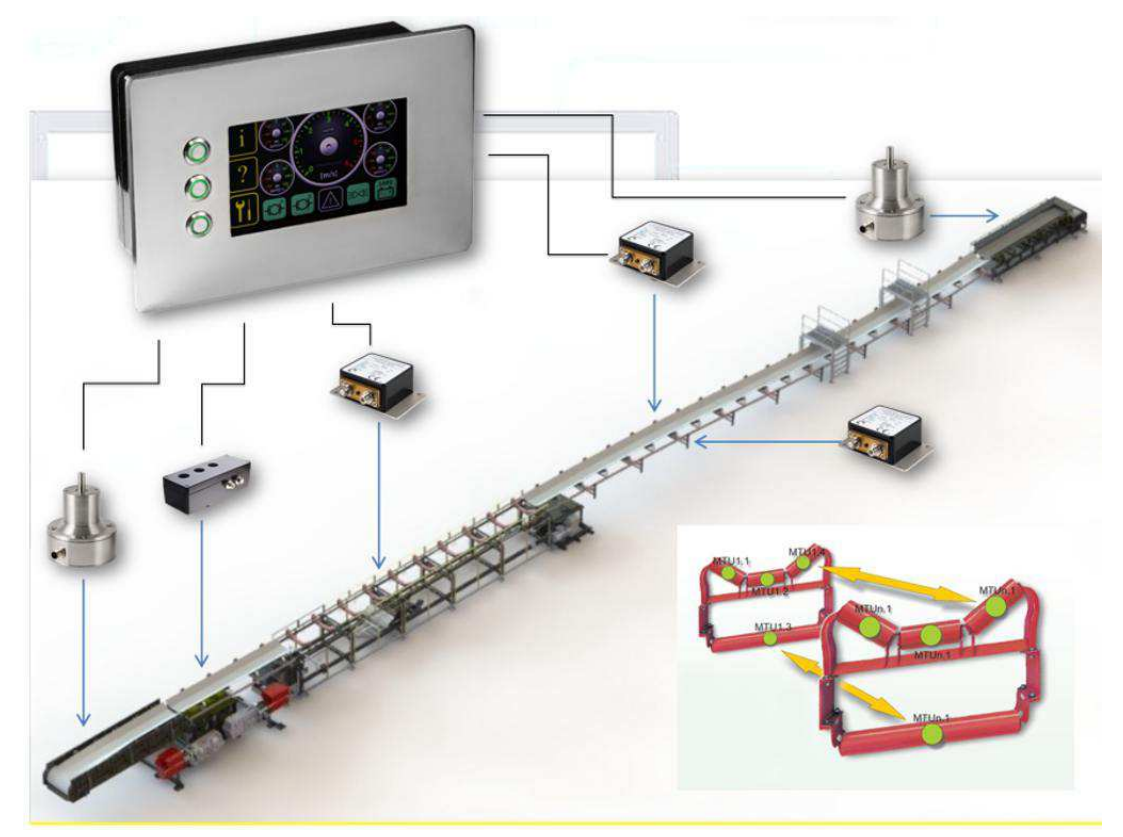

Fig. 5. Sensory network of belt conveyor rollers [30].

can be determined on the basis of the lowest speed of data transmission in radio charts.

Additionally, the following principles resulting from swarm phenomena are assigned to each data package so that the system can react to changes in a node structure, failures, nodes displacement):

1) the package matches its speed to the packages moving in paths of higher $W_{P}$ coefficient.

2) the package uses the path parallel to the optimal route (of highest known $W_{P}$ value), if its $W_{P}$ decreases.

3) the package uses the optimal path (of higher known $W_{P}$ value), if the $W_{P}$ coefficient of the current route decreases.

4) the package avoids transmission through the nodes that are marked as damaged.

5 ) the package can leave the present path, if the main transceiver station is found.

Local data, which is indispensable for the realization of tasks resulting from the above principles, are calculated and stored in nodes. There is no need to create a master routing table. The use of these rules causes that the group of MTUs creating the transmission connection automatically develops the structure of reliable transmission routes while neglecting the damaged units. The data frame in the SSKIR protocol is defined by four additional values:

- its own unique MTU identification number,

- $X$ and $Y$ coordinates defining the occupied position in the solution space of the communication path structure,

- the priority factor in the communication path of which the frame is an element,

- the baud rate for the $X$ and $Y$ dimensions, ie $v X$ and $v Y$.
The neighbours of frames with the number of a given MTU are called other frames that are in the MTU transmission range, ie those that are in a sufficiently short distance $d$ and simultaneously in the field of view, defined by the value of virtual angle $r$. In order to check whether a given frame $e$ of coordinates $e X$ and $e Y$ respectively, is a neighbour of MTU $b$ of coordinates $b X$ and $b Y$, it is necessary to check first whether the element is in a sufficiently short distance

$$
\sqrt{(e X-b X)^{2}+(e Y-b Y)^{2}}<d .
$$

If the inequality is not met, then the next rules are not checked, because a given frame from the MTU $e$ is certainly not a neighbour of frames from the MTU $b$. If the inequality is met, it is checked if the frame is in the virtual viewing angle $r$ by determining the angle $r_{1}$ under which the frame moves virtually

$$
r_{1}=\arctan \left(\frac{b v Y}{b v X}\right)
$$

and the virtual angle $r_{2}$ of the segment connecting the MTU $b$ frame with the MTU $e$ frame

$$
r_{2}=\arctan \left(\frac{e Y-b Y}{e X-b X}\right)
$$

assuming that $b v X \neq 0$ and $e X-b X \neq 0$. Then the absolute value of the angle difference is calculated, and the inequality checked

$$
\left|r_{1}-r_{2}\right|<r
$$

If the unevenness is met, then the frames come from neighbouring MTU. Next, the first rule is applied, and 
Throughput $(\mathrm{KB} / \mathrm{s})$

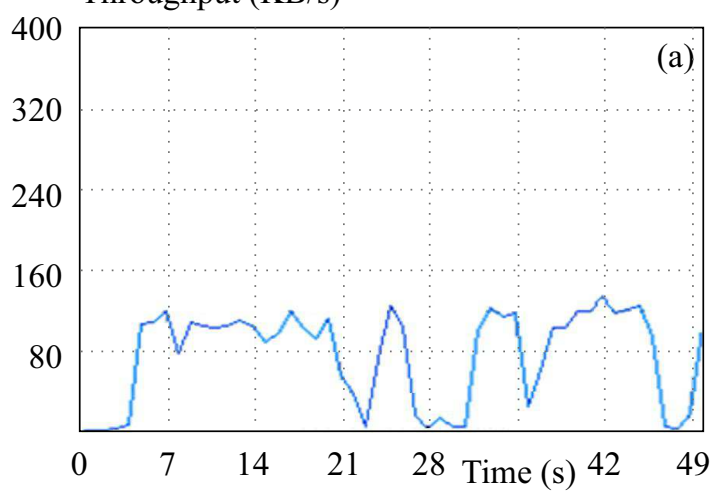

Throughput $(\mathrm{KB} / \mathrm{s})$

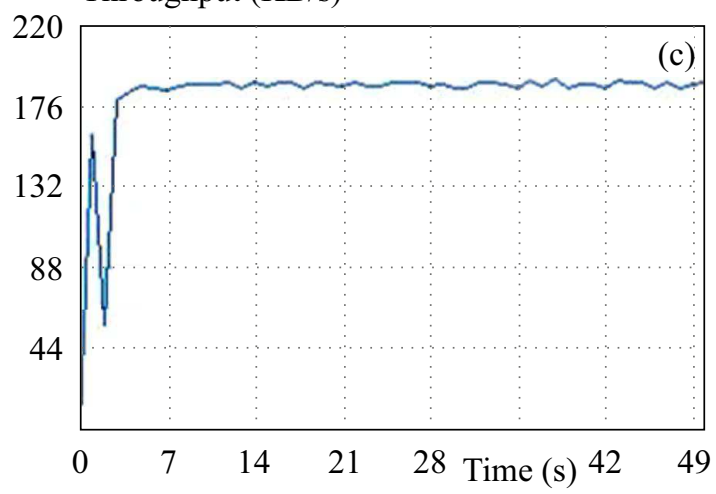

Throughput $(\mathrm{KB} / \mathrm{s})$

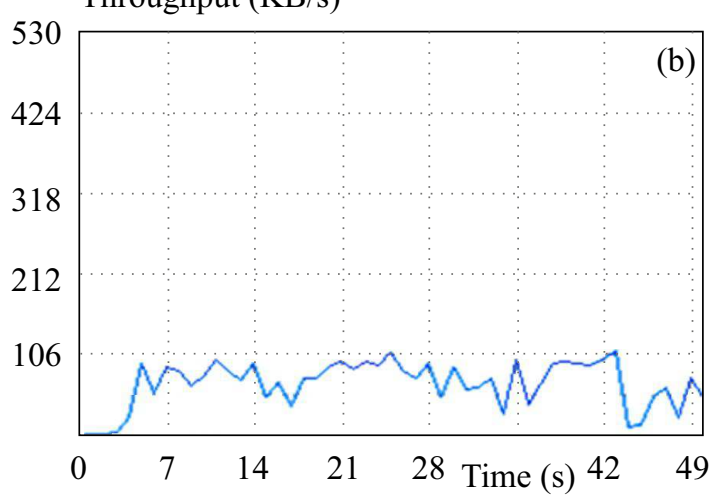

Throughput $(\mathrm{KB} / \mathrm{s})$

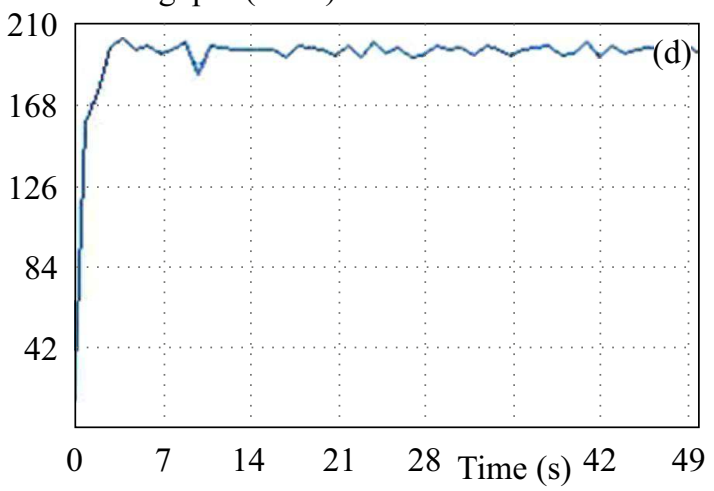

Fig. 6. Data rate in mesh network: (a) - consisting of 25 nodes with AODV protocol, (b) - consisting of 64 nodes with AODV protocol, (c) - consisting of 25 nodes with SSKIR protocol, (d) - consisting of 64 nodes with SSKIR protocol

each frame adjusts its path to frames from neighbouring MTU. One must calculate the average speed $v_{\text {avg }}$ of all frames from the neighbouring MTU (separately for the $v X$ and $v Y$ components) and then modify the frame transmission speed, taking into account the path priority factor, the current speed, and the calculated average, according to the following formulae:

$$
\begin{aligned}
& b v X=b v X+\left(W_{p}\left(v X_{\mathrm{avg}}-b v X\right)\right), \\
& b v Y=b v Y+\left(W_{p}\left(v Y_{\mathrm{avg}}-b v Y\right) .\right.
\end{aligned}
$$

To apply the second rule, the average number of frame jumps in the davg transmission path should be calculated in relation to frames from neighbouring MTU, and then the frame transmission speed should be modified in relation to neighbouring MTU. Formulae (9) are the result of the triangular similarity claim. The frame's position in the transmission path, whose speed is modified $b$ and the position of the neighbour $e$, is used

$$
\begin{aligned}
& d=\sqrt{(e X-b X)^{2}+(e Y-b Y)^{2}} \\
& b v X \leftarrow b v X+\frac{(e X-b X)\left(d-d_{\mathrm{avg}}\right)}{d} \\
& b v Y \leftarrow b v Y+\frac{(e Y-b Y)\left(d-d_{\mathrm{avg}}\right)}{d}
\end{aligned}
$$

The third rule shows that, when a frame in a path with a lower priority coefficient tries to carry out the transmission, competing with a frame with a higher priority, it should avoid it by modifying its speed. Formulae (10) also use the triangular similarity claim. Let $b$ be a lower priority frame competing with a frame from the neighbouring MTU, with a higher priority $e$. In regard to the above rule, the following formulae should be applied

$$
\begin{aligned}
& d=\sqrt{(e X-b X)^{2}+(e Y-b Y)^{2}} \\
& b v X \leftarrow b v X+\left(\frac{e X-b X}{d} d_{\min }-(e X-b X)\right) \\
& b v X \leftarrow b v X+\left(\frac{e Y-b Y}{d} d_{\min }-(e Y-b Y)\right)
\end{aligned}
$$

where, $d_{\min }$ is a preset minimum number of jumps in the transmission path, which should not be exceeded by the transmitted frame.

The last two rules are introduced to the system by modifying the fourth rule based on the dependencies (10). It should be noted that each frame can move with a certain maximum speed imposed by the physical system. In simulations, this speed should be limited and the following entered:

- limitations resulting from the presence of MTU in the emergency or start-up state (elements that frames should avoid creating transmission paths), and

- attractors in the form of main receiving and transmitting stations [39]. 


\section{Test results}

Stationary MESH network operating in WiFi technology $(802.11 \mathrm{~b})$, in which peer-to-peer connection between two nodes is established, where node A sends information to node $B$, is analysis subject. Analysis of MESH network efficiency was made on the basis of generated diagrams in relation to $B$ node receiving information including rate of incoming data batches and total incoming traffic.

The analysis was made based on obtained results from the scenarios network operation, simulated in NCTUnc programme, including the following assumptions:

1) Routing protocols in comparative analysis:

a) AODV - ad hoc On-Demand Distance Vector,

b) SSKIR - method basing on swarm algorithm,

2) Size of the network in mesh structure:

a) small network - $5 \times 5$ nodes,

b) big network $-8 \times 8$ nodes.

Distance between nodes is 200 metres (each nodes range covers only neighbouring nodes). That concerns networks of linear and mesh structure. Network of random structure $(25$ nodes) covers area $800 \times 800$ metres.

In Fig. 6, sample bit rates in the network achieved during simulation are presented. We can notice significant increase of throughput and stability of data transmission in SSKIR protocol being under development.

\section{Conclusions}

This technical solution for recovering the electricity from the movement of conveyor belt can be used in any industry where the supply of a new electrical installation is complicated and expensive. The electric energy generated and accumulated in the batteries can be used to power the devices monitoring the conveyor operation or the emergency lighting system during the conveyor stoppage.

The installation of the developed roller with an electricity generator will not require changes in the existing belt conveyor design. Therefore, it allow the user to power monitoring devices that signal or monitor the operation of the conveyor belt anywhere on its route.

In addition, the proposed solution, if implemented in belt conveyors operating in underground workings or in areas classified as potentially explosive, will meet the requirements of the ATEX Directive [7].

We are planning, together with the companies interested in implementation of this solution, to manufacture the roller-generator prototype and to conduct the prototype laboratory tests.

The method of self-organization of the communication system based on swarm algorithm enables implementing the state-of-the-art and effective routing technology in the networks of mesh technology also in those used in underground mining plants, especially as regards diagnostics, monitoring and protection of machines, in which the subassemblies, equipped with MTU nodes, can be treated as the components of the measuring swarm. It is especially important as regards safety of work of people in underground workings due to reliability of mesh networks.

The authors concept of the system is presented as well as factors for assessment of quality and principles of the suggested self-organization system functioning is given. Besides, results of tests indicating for increase of data transmission efficiency in the network equipped with the described algorithm in relation to the popular solutions met in practice. Current tests and simulation, are at the initial phase of the project, but the obtained results are promising and offer high potential of the suggested solution.

\section{Acknowledgements}

This work was supported by the European Regional Development Fund under the project CEBIA-Tech No. CZ.1.05/2.1.00/03.0089

\section{REFERENCES}

[1] P. Arabshahi, A. Gray, I. Kassabalidis, A. Das, S. Narayanan, M. Sharkawi and R.J. El Marks, "Adaptive Routing in Wireless Communication Networks using Swarm Intelligence", AIAA 19th Annual Satellite Communications System Conference, Toulouse, France, pp. 1-9, 2001.

[2] A. Bahr, "A long Story", Australian Longwall Magazine, March 2008.

[3] W. Bartelmus and R. Zimroz, "A new Feature for Monitoring the Condition of Gearboxes in Non-Stationary Operating Conditions", Mech Syst Signal Process vol. 23, no. 5, pp. 1528-1534. 2009.

[4] S. Basagni, M. Conti, S. Giordano and I. Stojmenovic, "Mobile ad hoc Networking", IEEE Press, New Jersey 2004.

[5] J. Bombor, "Artificial Intelligence in Pniówek Mine! Miners not Needed any More?" http://www.dziennikzachodni.pl/artykul/ 586769,sztuczna-inteligencja-w-kopalni-pniowekgornicyniepotrzebni,id,t.html\#czytaj_dalej, Dziennik Zachodni 2012.

[6] A. Boukerchea, B. Turgutb, N. Aydinc, A. Z. Mohammad, L. Bölönid and D. Turgut, "Routing Protocols in ad hoc Networks: A Survey", Elsevier Computer networks, vol 55, pp. 3032-3080, 15 Sep 2011.

[7] "Directive 2014/34/EU of The European Parliament and of the Council of 26 February 2014 on the Harmonisation of the Laws of the Member States Relating to Equipment and Protective Systems Intended for Use in Potentially Explosive Atmospheres".

[8] L. M. Feeney, "A Taxonomy for Routing Protocols in Mobile ad hoc Networks", SICS Technical Report T99/07, Oct 1999.

[9] D. He, Y. Pang, G. Lodewijks and X. Liu, "Healthy Speed Control of Belt Conveyors on Conveying Bulk Materials", Powder Technol vol. 327, pp. 408-419, 2018.

[10] C. Hou, T. Qiao, H. Zhang, Y. Pang and X. Xiong, "Multispectral Visual Detection Method for Conveyor Belt Longitudinal Tear Measurement", vol. 143, pp. 246-257, 2019.

[11] M. Ilyas, "The Handbook of ad hoc Wireless Networks", Florida Atlantic University, Florida, 2003, ISBN-13: 978-1-4200-4040-1 (eBook-PDF).

[12] D. Jasiulek, S. Bartoszek and J. Lubryka, "Efektywność wykorzystania i bezpieczeństwo techniczne górniczej obudowy zmechanizowanej", Maszyny Górnicze vol. 1/2019. 
[13] D. Jasiulek, J. Rogala-Rojek and K. Stankiewicz, "The Applicability of Artificial Intelligence Techniques in Control and Diagnostics of Mining Machinery", KOMTECH 2011. Monograph. ITG KOMAG, Gliwice, pp. 45-54, 2011.

[14] D. Jasiulek, "Monitoring of the Mining Powered Roof Support Geometry", DEStech Transactions on Computer Science and Engineering 5th International Scientific and Business Conference-Future Engineering, May 29-30, 2019 Ottarzew, Poland. DOI $10.12783 / \mathrm{dtcse} / \mathrm{fe} 2019 / 30685$.

[15] D. Jasiulek, "Monitoring the Operational Parameters of a Power Roof Suport", Journal of Machine Construction and Maintenance, Problemy Eksploatacji 2018, no. 2, pp. 109-115.

[16] J. Jura and S. Bartoszek, "KOGASTER - Instalacja Elektryczna Napȩdów Spalinowych", Masz. Gór. 2017 no 4, pp. 41-51.

[17] P. Kulinowski, "Analytical Method of Designing and Selecting Take-up Systems for Mining Belt Conveyors", Arch. Min. Sci. vol. 58, no. 4, 2013.

[18] J. Kwaśniewski, "The Use of Monitoring to Improve the Raliability and Endurance of Continous Coal Handling Systems", Archives of Mining Sciences, vol. 56, no. 4, pp. 651-664, 2012.

[19] S. Misra, S. C. Misra and I. Woungang, "Guide to Wireless ad hoc Networks", Springer-Verlag, London 2009.

[20] P. Mohapatra and S. V. Krishnamurthy, Ad hoc Networks, Technologies and Protocols, Springer, 2005.

[21] P. Novak, T. Kot, J. Babjak, Z. Konečny and W. Moczulski, "Implementation of Explosion Safety Regulations in Design of a Mobile Robot for Coal Mines" Applied Sciences; Basel Tom 8, No. 11, Nov 2018.

[22] B. Polnik, "Tests of the HK-1 Module of the Mobile Mining Machine", ECS Transactions 2019, no. 1. In: ABAF 2019, 20th International Conference on Advanced Batteries, Accumulators and Fuel Cells, Brno, 25-28 Aug 2019 pp. 389-396.

[23] B. Polnik, "An Innovative Power Supply System Dedicate for Roadheading Mining Machines", ECS Transactions 2018, no. 1. In: ABAF 2018, 19th International Conference on Advanced Batteries, Accumulators and Fuel Cells, Brno, 26-29 Aug 2018 pp. 349-362.

[24] "Pressure Monitoring System EH-PressCater", Elgor-Hansen, 2014, http://elgorhansen.com/assets/files/EN/automatyzacja/ Systemy/ENG_PresCater_(ENG).pdf.

[25] D. Prostański and J. Jonak, "An Application of Neural Networks in the Research Process of Mining using Conical Rotary Bits, Monograph", CMG KOMAG, Gliwice 2003, pp. 156-164.

[26] C. W. Reynolds, "Flocks, Herds, and Schools: A Distributed Behavioral Model", SIGGRAPH, Anaheim, USA 1987.

[27] S. K. Sarkar, T. G. Basavaraju and C. Puttamadappa, Ad hoc Mobile Wireless Networks Principles, Protocols, and Applications, Taylor \& Francis Group, 2007.

[28] J. Słoczyński, "Untypical Routing Algorithms", Lodz University of Technology, Łódź, 2004.

[29] A. Smolarek and T. Malinowski, "Routing Protocols in Ad hoc Networks, Teleinformatics Systems and Networks Conference", 2012, Proceedings, WWSI, Warszawa 2012, pp. 47-60.

[30] K. Stankiewicz, "Smart Mining Communication Systems", 5th International Scientific and Business Conference-Future Engineering, DEStech Transactions on Computer Science and Engineering, 2019.

[31] J. Świder, K. Herbuś and K. Szewerda, "Dynamic Analysis of Scraper Conveyor Operation with External Loads", In: CoSME '16, The 4th International Conference on Computing and Solutions in Manufacturing Engineering 2016, Brasov, Romania, Nov 3-4, 2016, pp. 1-6.

[32] E. Kalentev, Š. Václav, P. Bozek, A. Korshunov, and V. Tarasov, "Numerical analysis of the stress-strain state of a rope strand with linear contact under tension and torsion loading conditions", Advances in Science and Technology Research Journal, vol. 11, no. 2, pp. 231-239, 2017.
[33] M. Talarek and Ł. Orzech, "Testing the Electrostatic Characteristics of Polypropylene Fabric with Metallic Yarns, Intended for Use In Coal Mines Threatened by the Explosion Hazard, Part 1: Laboratory Tests", Electrostatics 2011, 13th International Conference on Electrostatics, Bangor University, Wales, UK, 2011 Apr 10-14. J. Phys. Conf. vol. 301, pp. 1-4, 2011.

34] K. Turczyński et al, "Pozyskiwanie energii elektrycznej z ruchu przenoś nika taś mowego. Opracowanie koncepcji sposobu generowania energii elektrycznej z ruchu przenośnika taśmowego", (Acquiring Electricity from the Conveyor Belt Movement. Development of the Concept of How to Generate Electricity from the Conveyor Belt Movement)", Gliwice: ITG KOMAG; 2017, Polish.

[35] T. Winkler, M. Dudek, W. Chuchnowski and J. Tokarczyk, "Internet Tools Supporting Planning of Underground Mining Transport." Coal Int.vol 1, pp. 44-48, 2012.

[36] https://www.shimano.com/en/.

[37] S. Vaclav, J. Peterka and P. Pokorny, "Objective method for assembly", Annals of DAAAM for 2007 \& Proceeding of the $18 T \mathrm{TH}$ Inter. DAAAM Symp. Intelligent Manufacturing \& Automation: Focus on Creativity, Responsibility, and Ethics of Engineering, 2007, pp. 797-798.

[38] P. Bozek and E. Pivarciova, "Flexible manufacturing system with automatic control of product quality", Strojarstvo. vol. 55, no. 3 (2013), online, p. [211-221].

39] B. Bako and P. Bozek, "Trends simulation and planning of manufacturing companies", Procedia Engineering, International Conference on Manufacturing Engineering and Materials, ICMEM 2016, vol. 149. International Conference on Manufacturing Engineering and Materials, ICMEM 2016, 6. - 10. June 2016, Nov Smokovec, Slovakia, (2016), online, pp. 571-575.

[40] M. Baranov, P. Bozek, V. Prajova, T. Ivanova, D. Novokshonov, A. $\mathrm{M}$ and Korshunov, "Constructing and calculating of multistage sucker rod string according to reduced stress", Acta Montanistica Slovaca, vol. 22, no. 2 (2017), pp. 107-115.

41] W. Bialy, "New devices used determining and assessing mechanical characteristics of coal", 13th SGEM GeoConference on Science and Technologies Geology, Exploration and Mining, SGEM2013 Conference Proceedings, June 16-22, 2013, vol. 1, BUGARIA ISBN 978-954-91818-7-6/ISSN 13142704. s. 547-554.

[42] W. Biały, "Coal cutting force measurment systems - (CCFM)", 14th SGEM GeoConference on Science and Technologies Geology, Exploration and Mining, SGEM2014 Conference Proceedings, June 17-26, 2014, vol. III, BUGARIA ISBN 978-619-7105 -09-4/ISSN 1314-2704. s. 91-98.

43] W. Biały and J. Fries, "Computer systems supporting the management of machines/equipment hard coal mines. Case study", Management Systems Production Engineering, 2019, vol. 27(3), pp. 138-143.

Received 23 January 2020

Krzysztof Mazurek, (PhD, Eng) graduated in 2004 with a master's degree in engineering in computer mechanics. In 2008 obtained a PhD degree in technical sciences in the discipline of mining and engineering geology. Since 2004 employed at the KOMAG Institute at the Division of Powered Roof Supports. He is a specialist in using the numerical methods in the strength calculations of powered roof supports components, individual roof supports and energy absorbing mechanical systems. He is co-author of developed construction documentation for several types of powered roof supports that are used in Polish hard coal mines. Authorship and co-authorship of 45 publications and co-authorship of 18 inventive projects submitted for protection at the Polish Patent Office reflects his innovative and creative professional activity. 
Marek Szyguła, (PhD, Eng) graduated in 1985 with the Master of Science in mechanics at the Faculty of Mechanical Engineering at the Silesian University of Technology in Gliwice. In 2002, at the AGH University of Science and Technology, obtained the doctoral degree in technical sciences in the discipline of machines designing and operation. Since 1986 employed at the KOMAG Institute of Mining Technology, currently is an assistant professor and head of the Division of Powered Roof Supports. He is a specialist in development of new longwall solutions for powered roof supports. He is coauthor of developed construction documentation for several types of powered roof supports that are used in Polish hard coal mines. Authorship and co-authorship of 57 publications and co-authorship of 46 inventive projects submitted for protection at the Patent Office of the Republic of Poland reflects his innovative and creative professional activity.

Karel Perutka received his PhD degree in 2007 at Tomas Bata University in Zlin, Faculty of Applied Informatics, Czech Republic, where he is a senior lecturer. Technical Cybernetics was the principal branch of his thesis. He is the author of one monograph about MATLAB, several book chapters about MATLAB and control theory, and author or co-author of more than fifty papers in the conference proceedings. He is a member of the organizing and reviewing committees of several conferences. He is teaching programming, electronics, microelectronics, software support of engineering computations. His main research interests are: adaptive control, real-time control, and control of multivariable systems.

Krzysztof Turczyński, (PhD, Eng) graduated in 1986 at the Czstochowa University of Technology in the field of mechanics specialization in machines technology. In 2007, obtained a PhD degree at the Czstochowa Technical University in machines designing and operation. Currently employed as an assistant professor at the KOMAG Institute of Mining Technology. He is the author and co-author of many publications, patents and monographs. He participated in implementation of Polish and European research projects.

Krzysztof Stankiewicz, (PhD, Eng) is Assistant Professor and Head of Mechatronic Systems Department in the Institute of Mining Technology KOMAG in Gliwice, where he develops new technologies in the field of automation, monitoring and control systems, ICT, power supply, drives, especially in relation to machines and mining processes. Specializes in the development of control techniques and methods, Internet technologies and automation. He cooperates with scientific centers in Poland and abroad, including AITEMIN (Spain), MRSL (Great Britain), HUNOSA (Spain), RWTH (Germany), University of Exeter (Great Britain), University of Nottingham (Great Britain), Fraunhofer Institute (Leipzig, Germany). Author or co-author of 97 scientific and technical publications. 